\title{
EVAPOTRANSPIRATION REQUIREMENT OF RICE AT MAPALANA IN THE WET ZONE OF SOUTHERN SRI LANKA
}

\author{
K. D. N. WEERASINGHE AND W. KATULLANDA \\ Department of Agronomy, Faculty of Agriculture, University of Rubuna, \\ Mapalana, Kamburupitiya, Sri Lanka.
}

(Date of receipt : 25 September 1987)

(Date of acceptance : 21 January 1988)

\begin{abstract}
A lysimeter experiment was conducted at the Mapalana Research Farm in order to estimate the evapotranspiration (ET) demand of rice in the southern wet zone. The measured values of ET were compared with pan evaporation (EP). The impact of meteorological factors on ET and EP of rice fields were assessed by the multiple regression method. The ET rate of rice varied in the range of $2-15 \mathrm{~mm} / \mathrm{day}$. The ET/EP ratio was almost one at transplanting reaching 1.9 at heading stage. The average ET/EP ratio for the entire growth period was 1.39 . It was revealed that wind is the most decisive factor governing ET and EP from rice fields.
\end{abstract}

\section{Introduction}

Water requirement of a vegetation is generally expressed as a function of the climate, soil and the plant. Hence, the amount of water needed by the crop. varies between species, in different locations and seasons.

Rice needs more water to sustain life than most other crops owing to its semi-aquatic nature. Its evapotranspiration rate is about $3-4 \mathrm{~mm} /$ day during the initial vegetative stages and $5-7 \mathrm{~mm} /$ day during reproductive to the medium dough stages. ${ }^{2,5,6}$ The average evapotranspiration rate in rice growing areas of Asia is about $4-9 \mathrm{~mm} /$ day. ${ }^{8}$

There are many reports indicating that the highest evapotranspiration rate of rice is at maximum tillering stage or at heading stage. ${ }^{5,6}$ It is evident in many locations of South East Asia that the transpiration rate of rice increases consistantly up to the heading stage and then declines. ${ }^{6}$ Nevertheless there are deviations from this general trend. For instance, some workers have observed the maximum rates at the tillering stage followed by an almost constant but lower rate in later stages. ${ }^{4}$

Research on water balance studies of rice in Sri Lanka is mostly restricted to the dry zone of the country. ${ }^{1}$ Therefore the objective of the present research was to find the average and peak period consumption of water by rice in the Southern wet zone of the Matara District. The influence of climatological factors on evaporation and evapotranspiration from the rice field is also discussed. 


\section{Materials and Methods}

The experiment was conducted at the University Research Farm, Mapalana, Matara District, during the Yala season (31st May-15th October) 1987.

Mapalana is located in the Agro-ecological region WL2 (Low country wet zone); the rainfall distribution of the area is typically biomodal with an annual precipitation of about $2385 \mathrm{~mm} .864 \mathrm{~mm}$ of rain is received during April - August and $911 \mathrm{~mm}$ in October - January. This constitutes $36.2 \%$ and $38.2 \%$ of the annual rainfall respectively. The mean air temperature is fairly uniform at around $28^{\circ} \mathrm{C}$ throughout the year. The relative humidity is usually higher in March - July and lower in January and February. The average relative humidity of the location is about $71.6 \%$.

The predominant soils of the area are Red yellow podzolic soils with strongly mottled subsoils and low humic gley soils.

Plastic containers with closed bottoms $(42 \mathrm{~cm}$ in height; 40 and $34 \mathrm{~cm}$ in diameter at the top and bottom ends) were used in the field lysimeter experiment. The containers were filled with $30 \mathrm{~kg}$ of soil taken from a paddy field and buried in the same field.

The soil taken for the experiment is sandy clay loam (clay $24 \%$; silt $16 \%$; and sand $60 \%$ ), slightly acidic ( $\mathrm{pH} 5.6$ ) with $2.5 \%$ of organic matter.

The set up of the lysimeter tanks was a complete randomized block layout with 3 replications. Water losses from the lysimeters were studied under 3 levels of submergence $(2.5,5.0,10.0 \mathrm{~cm}$.).

Evapotranspiration and evaporation losses from the containers cropped with rice (variety BG 379/2) and.bare soil were measured daily using a hook gauge. Three separate tanks were used to measure the evaporation from free water surface. Water level was readjusted to the required depth by adding water daily. Soil temperature of the containers were recorded daily in the morning and afternoon. Phenological observations were conducted weekly to record the growth differences of the plants.

All containers were kept weeded to avoid excess evapotranspiration losses. Basic fertilizer mixture (N:P:K: $-5: 15: 15)$ was added at the rate of $250 \mathrm{~kg} / \mathrm{ha}$. A top dressing of urea was added to the containers at a rate of $23 \mathrm{~kg} / \mathrm{ha}$ at tillering stage. Second top dressing was given $(\mathrm{N}: \mathrm{P}: \mathrm{K}-25: 0: 17$ ) at the rate of $95 \mathrm{~kg} / \mathrm{ha}$ at the flowering stage.

Measured evaporation and evapotranspiration data were correlated with the observed meteorological data viz. relative humidity, wind speed, air 
temperature and dew point temperature. The combined effect of meteorological factors on evaporation and evapotranspiration was assessed by the multiple regression method.

\section{Results and Discussion}

The evapotranspiration demand of transplanted rice varied from 2-15 $\mathrm{mm} /$ day (Figure 1). The total evapotranspiration demand for the season was $515,513,549 \mathrm{~mm}$. for $2.5,5.0$ and $10.0 \mathrm{~cm}$. submergence levels respectively: This consumption was for the entire growth period excluding the first two weeks in the nursery and the last two weeks prior to harvest. Evapotranspiration rate increased with the increasing depth of submergence. However, the evapotranspiration rates at different levels of submergence appear to be not significant.

In the first, 20 days of growth, evapotranspiration rate was slightly higher compared to the evaporation from bare soil or free water surface (Figure 1). The evapotranspiration gradually increased after 20 days from transplanting, which is probably associated with the growth and development of the assimilatory surface.

Evapotranspiration had a highly significant relationship $(r=0.93)$ with evaporation during the initial stages (up to 30 days from transplanting) and also in the later stages, $(r=0.89)$ (ie. after $80-105$ days from transplanting) However, in the middle of the growing season (30-80 days from transplanting) the correlation between evaporation and evapotranspiration was low $(r=0.35)$. This may be due to the high transpiration rate coinciding with larger leaf area.

The ET/EP ratio was almost 01 at transplanting, reaching 1.9 between 40 - 50 days from transplanting (Figure 2). The average ET/EP ratio for the entire period of growth was 1.39 .

Rice had two maxima of evapotranspiration in the tillering and heading stages (Figure 1). According to Kung et al. and Grist, ${ }^{3,4}$ the rice crop is in great need of water during the maximum tiller number stage and in the heading stage. Nevertheless in most of the experiments the rate of evapotranspiration observed at heading was much greater than the rate at maximum tillering stage. 6 . As reported in Thailand ${ }^{4}$ rice may have higher peak rate at tillering stage:

The differences of peak rates at tillering and heading phases may be associated with the morphological characteristics of the variety, such as medium to high tillering capacity accompanied with thick erect leaves and lodging resistance. The peak demand of water on the 6 th and 7 th weeks may 


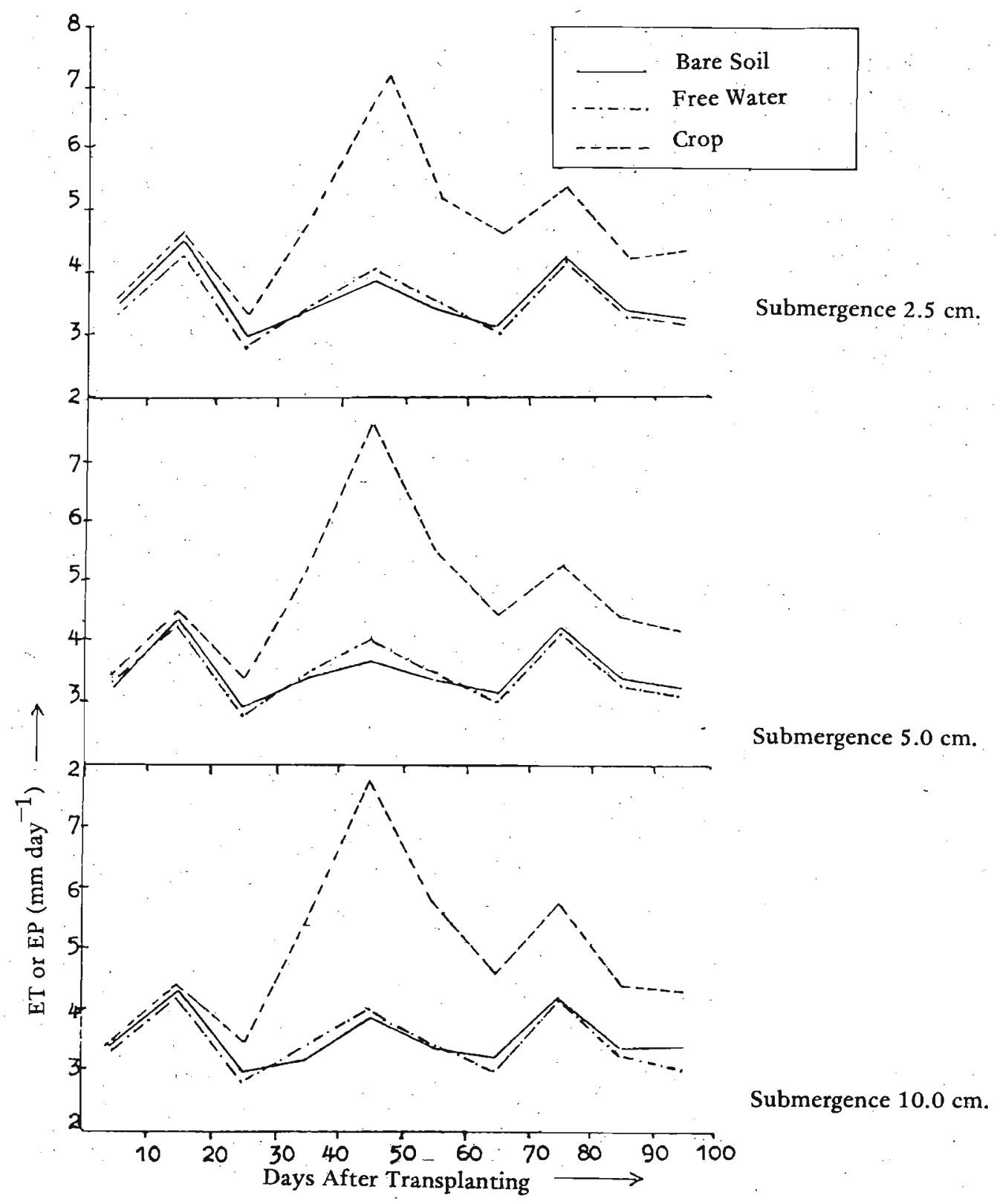

Figure 1. Water losses from the free water surface, bare soil and the cropped soil at various levels of submergence. 


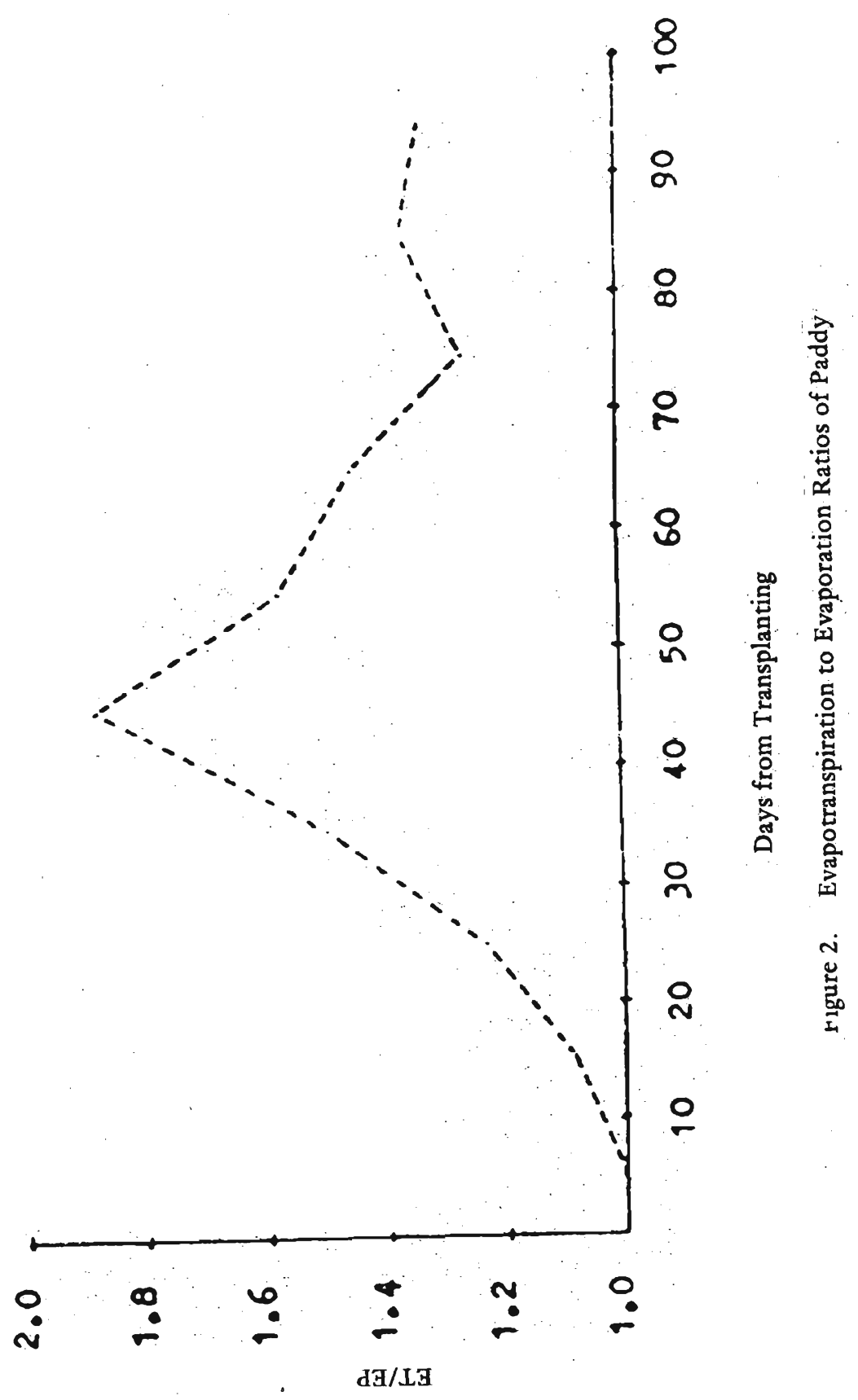


be associated with the existing meteorological conditions (high wind speed and temperature) and development of tillers and rapid increase in leaf area after the 2nd application of fertilizer late in the 4th week.

Evaporation of water from the bare soil and free water surface in lysimeters were similar. The evaporation from the bare soil was maximum when the level of submergence was $10.0 \mathrm{~cm}$. (Figure 1). The evaporation from the free water surface and bare soil had a correlation of $0.95,0.94$ and 0.91 for the respective submergence levels of $2.5,5.0$ and $10.0 \mathrm{~cm}$.

The recorded values of the class A pan evaporation by the meteorological station were high compared to the evaporation from the free water surface, of the lysimeters (Figure 3 ). This may be due to the high humidity in the paddy fields. The correlation between measured values of class A pan evaporation and the evaporation from lysimeter tanks were high $(r=0.92)$, the regression equation for these two variables could be given as,

$\mathrm{EW}=0.808 \mathrm{EP}+0.317$

$(\mathrm{EW}=$ Evaporation from rice fields $\mathrm{mm} /$ day, $\mathrm{EP}=\mathrm{Pan}$ evaporation $\mathrm{mm} /$ day) .

The effect of different meteorological factors such as air temperature; dew point temperature; wind speed and relative humidity on evaporation and evapotranspiration is indicated by the correlation coefficients (Table 1).

Table 1. Possible correlations of meteorological factors on evaporation and evapotranspiration.

\begin{tabular}{|c|c|c|}
\hline Meteorological factor & $\begin{array}{l}\text { Pan evaporation } \\
(\mathrm{EP})(\mathrm{mm} / \text { day })\end{array}$ & $\begin{array}{l}\text { Evapotranspiration (ET) } \\
\text { rate of rice ( } \mathrm{mm} / \mathrm{day})\end{array}$ \\
\hline Air temperature $(\mathrm{X} 2) \mathrm{C}$ & $0.5513^{*}$ & $0.3959^{*}$ \\
\hline Dew point temperature $(\mathrm{X} 3) \mathrm{C}$ & 0.1805 & $0.4565^{*}$ \\
\hline Wind speed $(X 4) \mathrm{m} / \mathrm{s}$ & $0.8547^{*}$ & $0.6879^{*}$ \\
\hline Relative humidity \% (X5) & 0.2272 & 0.1322 \\
\hline
\end{tabular}

It is apparent that wind is highly correlated with pan evaporation and the evapotranspiration rate of the rice fields. The correlation between air temperature and pan evaporation is also significant.

The analysis of variance of meteorological factors on evaporation (EP) and evapotranspiration (ET) as regressions are given in the Tables 2(a) and 


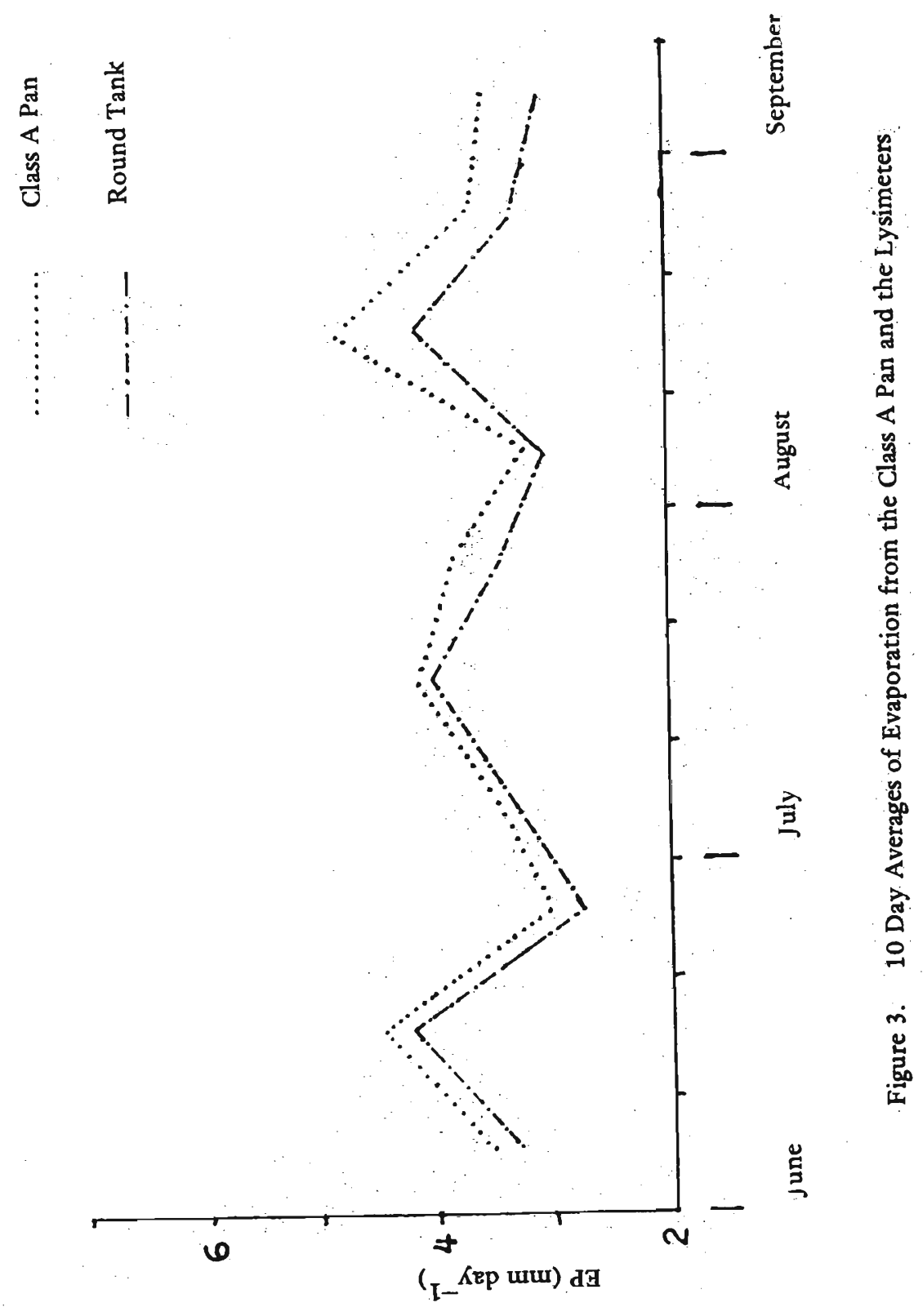


2 (b). It is clear that the impact of wind wind on evaporation or evapotranspiration is highly significant whether or not air temperature, relative humidity or dew point temperature have an effect on it. Thus it was revealed that wind is the most decisive factor governing pan evaporation and evapotranspiration from rice fields.

Table 2 (a). Analysis of variance of the different meteorological factors over the evaporation.

\begin{tabular}{|c|c|c|c|c|}
\hline Source of variance & S.S. & D:F. & M.S. & F. Value \\
\hline Regression of $\mathrm{X} 2 \times 3 \times 4 \times 5$ & 59.129 & 4 & 14.782 & $31.7^{*}$ \\
\hline $\mathrm{X} 3 \mathrm{X} 4 \mathrm{X} 5$ ignoring $\mathrm{X} 2$ & 58.577 & 3 & 19.526 & $41.7^{*}$ \\
\hline $\mathrm{X} 4 \mathrm{X} 5$ ignoring $\mathrm{X} 2 \mathrm{X} 3$ & 58.537 & 2 & 29.268 & $63.75^{*}$ \\
\hline $\mathrm{X} 4$ ignoring $\mathrm{X} 2 \mathrm{X} 3 \mathrm{X} 5$ & 58.528 & 1 & 58.528 & $130.15^{*}$ \\
\hline $\mathrm{X} 5$ ignoring $\mathrm{X} 2 \times 3 \times 4$ & 4.135 & 1 & 4.135 & 2.012 \\
\hline $\mathrm{X} 3$ ignoring $\mathrm{X} 2 \mathrm{X} 4 \mathrm{X} 5$ & 2.609 & 1 & 2.609 & 1.016 \\
\hline $\mathrm{X} 2$ ignoring $\mathrm{X} 3 \times 4 \times 5$ & 24.350 & 1 & 24.350 & $20.96^{*}$ \\
\hline $\begin{array}{l}X 2 \text { assuming } X 3 \times 4 \times 5 \\
X 3 \text { assuming } X 4 \times 5\end{array}$ & 0.5527 & $\mathbf{1}$ & 0.5527 & 1.185 \\
\hline $\begin{array}{l}\text { ignoring } X 2 \\
\text { Effect of X5 when } X 4\end{array}$ & 0.04 & 1 & 0.04 & 0.08 \\
\hline Effect of $X 4$ when $X 5$ & 0.0082 & 1 & 0.0082 & 0.017 \\
\hline in the model & 54.4 & 1 & 54.4 & $116.6^{*}$ \\
\hline $\begin{array}{l}\text { Error } \\
\text { Total } \\
X 2-\text { air temperature } C^{\circ} \\
X 3-\text { dew point } t^{\circ} \\
X 4-\text { wind speed } \mathrm{m} / \mathrm{s} \\
X 5-\text { relative humidity } \%\end{array}$ & $\begin{array}{l}20.984 \\
80.113\end{array}$ & $\begin{array}{l}45 \\
49\end{array}$ & 0.466 & - \\
\hline
\end{tabular}


Table 2 (b). Analysis of variance of the different meteorological factors over the evapotranspiration.

\begin{tabular}{|c|c|c|c|c|}
\hline Source of variance & S.S. & D.F. & M.S. & F. value \\
\hline Regression of $\mathrm{X} 2 \mathrm{X} 3 \mathrm{X} 4 \mathrm{X} 5$ & 167.478 & 4 & 41.869 & $15.877^{*}$ \\
\hline $\mathrm{X} 2 \times 3 \times 5$ ignoring $\mathrm{X} 4$ & 96.796 & 3 & 32.265 & $7.838^{*}$ \\
\hline $\mathrm{X} 3 \times 4 \times 5$ ignoring $\mathrm{X} 2$ & 167.409 & 3 & 55.803 & $21.619^{*}$ \\
\hline $\mathrm{X} 2 \mathrm{X} 4 \mathrm{X} 5$ ignoring $\mathrm{X} 3$ & 136.017 & 3 & 45.339 & $13.892^{*}$ \\
\hline $\mathrm{X} 2 \times 3 \times 4$ ignoring $\mathrm{X} 5$ & 167.382 & 3 & 55.79 & $21.61^{*}$ \\
\hline $\mathrm{X} 4 \times 5$ ignoting $\mathrm{X} 2 \mathrm{X} 3$ & 135.961 & 2 & 67.981 & $21.274^{*}$ \\
\hline $\mathrm{X} 2 \mathrm{X} 3$ ignoring $\mathrm{X} 4 \mathrm{X} 5$ & 95.53 & $\dot{2}$ & 47.768 & $11.778^{*}$ \\
\hline $\mathrm{X} 5$ ignoring $\mathrm{X} 2 \times 3 \times 4$ & 4.99 & 1 & 4.99 & $0.854^{*}$ \\
\hline $\mathrm{X} 2 \times 5$ ignoring $\mathrm{X} 3 \mathrm{X} 4$ & 45.384 & 2 & 22.692 & $4.43^{*}$ \\
\hline $\mathrm{X} 3 \mathrm{X} 4$ ignoring $\mathrm{X} 2 \mathrm{X} 5$ & 167.478 & 2 & 83.739 & $33.094^{*}$ \\
\hline $\mathrm{X} 4$ ignoring $\mathrm{X} 2 \mathrm{X} 3 \mathrm{X} 5$ & 135.401 & 1 & 135.401 & $43.114^{*}$ \\
\hline $\mathrm{X} 2$ ignoring $\mathrm{X} 3 \mathrm{X}^{*} \times 5$ & 44.839 & 1 & 44.839 & $8.919^{*}$ \\
\hline $\mathrm{X} 3$ ignoring $\mathrm{X} 2 \mathrm{X} 4 \mathrm{X} 5$ & 59.625 & 1 & 59.625 & $12.635^{*}$ \\
\hline $\mathrm{X} 2$ assuming $\mathrm{X} 3 \mathrm{X} 4 \mathrm{X} 5$ & 0.069 & 1 & 0.069 & 0.026 \\
\hline $\mathrm{X} 5$ assuming $\mathrm{X} 2 \mathrm{X} 3 \mathrm{X} 4$ & 0.096 & 1 & 0.096 & 0.048 \\
\hline $\mathrm{X} 3$ assuming $\mathrm{X} 2 \mathrm{X} 4 \mathrm{X} 5$ & 31.461 & 1 & 31.461 & $11.93^{*}$ \\
\hline $\mathrm{X} 4$ assuming $\mathrm{X} 2 \mathrm{X} 3 \mathrm{X} 5$ & 70.68 & 1 & 70.68 & $26.803^{*}$ \\
\hline \multicolumn{5}{|l|}{$\begin{array}{l}X 4 \text { assuming } X 2 \text { X } X 3 \\
\text { Effect of } X 3 \text { when } X 4\end{array}$} \\
\hline in the model & 32.077 & 1 & 32.077 & 2.63 \\
\hline \multicolumn{5}{|l|}{ Effect of $X 4$ when $X 3$} \\
\hline in the model & 101.853 & 1 & & \\
\hline Error & 118.668 & 45 & 2.637 & - \\
\hline Total & 286.146 & 49 & & \\
\hline
\end{tabular}


The regression lines for evaporation (EP) and evapotranspiration (ET) when wind speed $(\mathrm{X} 4)$ is included to the regression models would be,

$\mathrm{EP}=1.4676+0.7734 \mathrm{X} 4$ and

$\mathrm{ET}=2.4857 \mathrm{X} 4-2.9853$

(EP and ET; (mm/day), $\mathrm{X} 4 ;(\mathrm{m} / \mathrm{s})$ respectively.

These regression lines would be a useful tool in estimating Evaporation (EP), and Evapotranspiration (ET), from the rice fields at Mapalana.

\section{Acknowledgements}

The authors gratefully acknowledge the assistance of many members of the staff of the Agricultural Engineering laboratory, University of Ruhuna, in respect of this paper.

Special mention must be made of Miss. Indrani Weerasinghe for her valuable help in the statistical analysis.

\section{References}

1. BANDARA, B.W.M.D. \& PAIN, A.N. (1981). Water balance of rice on the Grumosols in the command area of Giant's tank, Trop. Agriculturist, Dept. of Agriculture 137: $123-136$.

2. DATTA, S.K. DE. (1981). Principles and practices of rice production, John Wiley \& Sons.

3. GRIST, D.H. (1959) Rice, Trop. Agriculture. Series, 3rd ed. Longmans: London 39-42.

4. KUNG, P.C., ATTHAYODHIN \& DRUTHABANDHU, S. (1965) Determining water requirement of rice by field measurement in Thailand, IRC Newsl. 14(4).

5. STANSEL, J.W. \& FRIES, R.E. (1980). A conceptual agromet rice yield model, Prod. of a sym. on the agro-meteorology of the rice crop, IRRI, Los Banos, Philippines 201-212.

6. TOMAR, V.S. \& O'TOOLE, J.C. (1979) Evapotranspiration from rice fields, IRRI Res. pap. ser. No. 34, IRRI, Los Banos, Philippines.

7. TOMAR, V.S. \& O'TOOLE, J.C. (1980) Measurement of evapotranspiration in rice; Proc. of a sym. on the agro-meteorology of the rice crop, IRRI, Los Banos, Philippines 87-94.

8. WICKHAM, T.J. \& SEN, C.N. (1978) Water management for lowland rice: water requirements and yield response. Soils and Rice, IRRI, Los Banos, Philippines. 